\title{
EVENTOS RELIGIOSOS E SUAS PRÁTICAS DE LETRAMENTO EM COMUNIDADES MULTILÍNGUES E MULTICULTURAIS
}

\author{
RELIGIOUS EVENTS AND THEIR LITERACY PRACTICES IN MULTILINGUAL AND \\ MULTICULTURAL COMMUNITIES
}

\author{
Neiva Maria Jung \\ Universidade Estadual de Maringá \\ Jakeline Semechechem \\ Universidade Estadual de Maringá - Bolsista do CNPq Brasil
}

\begin{abstract}
Resumo
Neste artigo temos como objetivo descrever e analisar práticas sociais letradas em eventos de letramento religiosos em duas comunidades do Paraná: uma comunidade multilíngue (alemão, português e brasileiro) e outra multilíngue (português, ucraniano, polonês, alemão, italiano). Para tanto, partimos dos Novos Estudos de Letramento (NLS) (STREET, 2003, 2004, BAINHAM, 2004), discutindo conceitos, como letramentos multilíngues (MARTIN-JONES; JONES, 2000; MARTIN-JONES, 2009), biletramento (HORNBERGER, 2003a, 2003b, 2003c) e letramento como prática social (BARTON, 2007). Os procedimentos metodológicos adotados foram: anotações de campo a partir de observação participante em eventos das comunidades, como catequese, missas, encontros religiosos; entrevistas e coleta de textos escritos impressos e da internet, o que possibilitou a triangulação de dados. Os resultados da análise evidenciam que nas duas comunidades há uma configuração diferenciada da realidade multilíngue, co-construída nas práticas de letramento religiosas.
\end{abstract}

Palavras-chave: Letramento. Multilinguismo. Eventos religiosos.

\begin{abstract}
In this article we describe and analyze social literacy practices in religious literacy events in two communities in Paraná: a multilingual community -German, Portuguese and Brazilian - and another one - Portuguese, Ukrainian, Polish, German, and Italian. We approach concepts as New Literacy Studies (NLS) (STREET, 2003, 2004, BAINHAM, 2004), Multilingual Literacies (MARTIN-JONES; JONES, 2000; MARTIN-JONES, 2009), Biliteracy (HORNBERGER, 2003a, 2003b, 2003c), and literacy as a social practice (BARTON, 2007). The proposed procedures are focused on notes from participant observation of some events, in the communities, such as catechesis, celebration of mass, religious meetings, interviews and written texts from the Internet. It also allowed for triangulation of data within each case study. The results showed that there is a different configuration of the multilingual reality that is coconstructed in the religious practices of literacy.
\end{abstract}

Keys-word: Literacy. Multilinguism. Religious events. 


\section{INTRODUÇÃO}

Rosowsky (2008) trabalha com letramento litúrgico. Para ele, uma das características desse letramento seria uma presença maior de leitura de textos religiosos, em comparação com a escrita. Além disso, eventos litúrgicos são corriqueiros, e as pessoas geralmente participam de algum deles ao longo de suas vidas. Em termos de pesquisa, no entanto, são eventos invisibilizados em relação a práticas escolarizadas; poucos estudos têm sido desenvolvidos sobre esses eventos. Além disso, dos estudos sobre letramento litúrgico, a maioria foi realizada em contextos monolíngues.

Procurando, assim, contribuir para preencher essa lacuna, este artigo busca, a partir de duas pesquisas do tipo etnográficas, descrever e analisar eventos religiosos e suas práticas de letramento em dois municípios no Paraná, São Mateus ${ }^{1}$ e São Josafat. Mais especificamente, pretendemos compreender em que consistem tais eventos e suas práticas e de que forma estão (ou não) articulados com as realidades multilíngues locais, uma vez que as duas comunidades do Paraná foram colonizadas em épocas e por grupos étnicos diferenciados. Para dar conta desse objetivo, organizamos o artigo do seguinte modo: na primeira seção apresentamos a perspectiva dos Novos Estudos de Letramento, na segunda, definições e uma discussão sobre letramento em comunidades multilíngues e multiculturais e, na terceira, estudos realizados sobre eventos litúrgicos. Na quarta, descrevemos a construção social do letramento nos eventos religiosos das comunidades e na quinta seção destacamos as implicações desses eventos e práticas de letramento para a manutenção de uma identidade local e para eventos de letramento escolares.

\section{NOVOS ESTUDOS DE LETRAMENTO (NLS)}

A perspectiva dos Novos Estudos de Letramento “New Literacy Studies” (BARTON; HAMILTON, 2000; GEE, 1990, HEATH, 1983, STREET, 1993) é uma ruptura com o modelo autônomo de letramento (STREET, 1995). De acordo com este modelo, a escrita é autônoma e neutra, o seu uso independe do contexto social (STREET, 1984), portanto, os modos de fazer uso da leitura e da escrita são universais (STREET, LEFSTEIN, 2007).

Segundo Street (1995), os usos da leitura e da escrita são socialmente determinados, têm valor e significado específico para cada comunidade, portanto, não podem ser tratados isoladamente como "neutros", como na perspectiva desse modelo. Desse modo, os Novos Estudos de Letramento (NLS) representam uma nova tradição de pesquisa, por considerarem a natureza do letramento, focando não tanto na aquisição de competências, mas no que significa pensar o letramento como uma prática social (STREET, 1995), o que implica reconhecer os múltiplos letramentos que variam de acordo com o tempo e o espaço e estão articulados com as relações de poder (STREET, 2003).

Segundo Baynham (2004), essa perspectiva vem se constituindo há três gerações de estudos, sendo a primeira, segundo esse autor, de Heath (1983), Scribner e Cole (1981), a segunda de Barton e Hamilton (1998), Besnier (1993), Bruce Kulick e Stroud (1993),

\footnotetext{
${ }^{1}$ Os nomes dos municípios, das comunidades rurais e dos participantes da pesquisa são pseudônimos.
} 
Prinsloo Breier (1996) e a terceira por pesquisadores atuais (STREET, 2003; STREET; LEFSTEIN, 2007).

Street (2003) em seu artigo intitulado “O que há de novo nos Novos Estudos de Letramento" discute o que há de novidade no termo, uma vez que os Novos Estudos de Letramento desenvolvem conceitos já discutidos. Ele destaca a necessidade de se estudar as questões tanto locais das práticas situadas do letramento quanto globais, considerando também os aspectos de multimodalidade. Street e Lefstein (2007), por sua vez, destacam como novas as contribuições dos estudos qualitativos etnográficos para os Novos Estudos de Letramento.

Em síntese, os Novos Estudos de letramento privilegiam o letramento em nível local, ênfase que já recebeu algumas críticas na suposição de que privilegiaria o local em detrimento do global. Street (2004) desafia essas críticas e argumenta que o letramento é sempre instanciado e realizado em práticas locais, portanto, tarefa dos estudos de letramento seria prestar contas da rica e complexa multimodalidade no contexto local e global das relações. Desse modo, os Novos Estudos de Letramento estão em um período em que a multimodalidade é saliente, além da relação entre o local e o global (STREET, 2004).

A etnografia do letramento não só pode dar conta das formas culturais de letramentos situados, mas também de estruturas de poder para definir e compreender tais práticas. Trata-se, no entanto, de uma tarefa complexa destacar o que é exterior ou interior, o que é uma imposição externa ou resistência local, pois é um processo dialético (STREET, 2004), por isso a relevância de estudos etnográficos nos Novos Estudos do Letramento, cujo intuito é dar conta tanto das questões locais e globais, para compreender não só como as práticas de letramento acontecem, mas por que e o que elas significam.

Para uma descrição situada, Barton e Hamilton (2000) apresentam seis proposições a respeito da natureza do letramento. Tais proposições, seguindo a forma como foram apresentados pelos pesquisadores, estão sintetizadas no quadro, a seguir.

- O letramento é mais bem compreendido como um conjunto de práticas sociais; tais práticas sociais podem ser inferidas dos eventos que são mediados por textos escritos;

- existem diferentes letramentos associados com diferentes domínios da vida;

- as práticas de letramento são padronizadas pelas instituições sociais e pelas relações de poder, e alguns letramentos são mais dominantes, visíveis e influentes que outros;

- as práticas de letramento têm propósitos e se encaixam em metas sociais e práticas culturais mais amplas;

- o letramento é historicamente situado;

- as práticas de letramento mudam, e novas práticas são frequentemente adquiridas através de processos de aprendizagem informal e construção do sentido. (BARTON; HAMILTON, 2000, p. 8).

QUADRO 1. Letramento como prática social 
De acordo com as proposições, os textos são uma parte dos eventos de letramento, uma vez que o estudo do letramento é o estudo dos textos e como eles são produzidos e usados, ou melhor, letramento é o conjunto de práticas sociais que se constroem a partir de eventos mediados por textos escritos. Neste sentido toda situação em que a escrita faz parte da interação e do processo interpretativo dos participantes constitui um evento de letramento e a prática de letramento são os modos culturais de usar a linguagem escrita que as pessoas constroem em suas vidas ao participarem de diferentes eventos, em diferentes domínios sociais. Trata-se de compreender o letramento a partir da metáfora da ecologia (BARTON, 2007), ou seja, o conceito de práticas de letramento oferece um caminho para compreender a inter-relação entre as atividades de leitura e de escrita e a estrutura social na qual tais atividades acontecem e que elas ajudam a mudar.

A base concreta para a observação são os eventos de letramento. Em outras palavras, para conhecer e descrever práticas de letramento, os estudos descrevem eventos de letramento do cotidiano das pessoas. De acordo com Hamilton (2000):

[...] eventos de letramento visíveis são apenas a ponta do iceberg: as práticas de letramento podem apenas ser inferidas a partir de evidências observáveis, porque elas incluem recursos invisíveis, tais como conhecimento e sentimento; elas incorporam valores e propósitos sociais; e são parte de um contexto em constante mudança, tanto espacial como temporalmente (p. 18), (grifo no original), (tradução nossa).

Os eventos de letramento são a parte concreta observável. Uma mudança espacial e temporal caracteriza, em princípio, uma mudança no evento. Uma mudança de prática é observável nos modos de interagir com a leitura e a escrita, ou seja, a mudança de modos culturais de interagir com o texto escrito caracteriza uma mudança de prática, conforme a quarta proposição do Quadro 1. Tusting (2000) alerta que é necessário estar continuamente atento para o fato de que as práticas de letramento emergem de repetições rítmicas de eventos de letramento similares.

A partir dessas proposições, descrevemos na seção 5 os eventos de letramento religiosos de duas comunidades, em nível micro, sem perder de vista a configuração multilíngue da comunidade, o nível macro.

\section{LETRAMENTO EM CONTEXTOS MULTILÍNGUES E MULTICULTURAIS}

A partir dos Novos Estudos de Letramento, surgiram termos e definições variadas para referir-se ao letramento, como multiletramento, letramentos múltiplos, letramento digital, visual, político, letramento crítico, numeramento, biletramento e letramentos multilíngue (STREET, 2000, STREET; LEFSTEIN, 2007).

A diversidade de culturas, de línguas e de variações em uma mesma língua, o multiculturalismo e o multilinguismo tomaram proporção a partir dos Novos Estudos de Letramento. Alguns conceitos foram desenvolvidos na perspectiva de enfocar 0 letramento nesses contextos, como letramento multilíngue (MARTIN-JONES; JONES, 2000) e biletramento (HORNBERGER, 2003a, 2003b, 2003c). 
Letramento multilíngue inclui linguagens e práticas de letramento entre pessoas de diferentes grupos linguísticos, de minorias (MARTIN-JONES; JONES, 2000). As autoras abordam, a partir da tradição dos Novos Estudos de Letramento (NLS), o letramento plural como prática social, adotando o termo multilíngue porque ele daria conta da multiplicidade e complexidade dos propósitos comunicativos, associados com as diferentes linguagens faladas ou escritas do repertório de um grupo.

Martin-Jones e Jones (2000) ressaltam que o termo multilíngue é mais útil do que o termo bilíngue, pois centra sua atenção nos múltiplos modos e códigos que as pessoas usam no seu repertório comunicativo, quando falam ou escrevem, enquanto o termo bilíngue só evoca a distinção entre dois códigos. Em práticas de letramento, o que configura a situação como multilíngue não é somente o texto escrito em mais de uma língua ou variedade de uma língua, mas também a conversa que gira em torno desse texto. Para as autoras, mesmo que a norma para a produção de textos no contexto institucional seja monolíngue, a conversa pode ser multilíngue.

Em relação à combinação do termo multilíngue e letramentos, as autoras esperam que

Ao combinar os termos "multilíngue" e "letramentos", temos a intenção de sinalizar que as configurações de língua e letramentos, consideradas aqui, não são vistas sob uma ótica determinista. Queremos também ressaltar que as práticas específicas que envolvem o uso de diferentes línguas faladas e escritas são sempre submetidas a um processo de reafirmação e redefinição dentro dos repertórios individuais relacionados à vida individual e a um nível cultural mais amplo (p. 8), (tradução nossa).

Desse modo, com a opção letramento multilíngue procuram dar conta das práticas que envolvem o uso de diferentes línguas faladas e escritas numa perspectiva que considera tanto o repertório individual como a questão cultural mais ampla.

Hornberger (2003), por sua vez, usa o termo biletramento para definir toda instância na qual a comunicação se desenvolve em duas (ou mais) línguas em torno de um texto escrito. O modelo proposto por Hornberger consta de quatro espaços tridimensionais e encaixados, compostos dos continua que caracterizam os contextos, meios, conteúdos e desenvolvimento do biletramento. O seu modelo permite demonstrar as relações múltiplas e complexas entre o bilinguismo e o letramento. Em cada continuum, haveria uma infinidade de pontos que se relacionam inevitavelmente com os demais pontos. Quanto mais os contextos de aprendizagem dos indivíduos permitam que eles usufruam de todos os aspectos dos continua, maiores são as chances de realização de um completo biletramento (HORNBERGER, 2001).

O modelo de biletramento é, segundo a pesquisadora, um esquema ecológico proposto como instrumento e guia para investigação, ensino e planificação de línguas em contextos multilíngues e que tem servido de fundamento para pesquisas na área, tanto nos contextos dos EUA, como em contextos internacionais (HORNBERGER, 2003).

Street (2000) faz algumas considerações sobre as novas definições de letramento que surgiram na perspectiva dos Novos Estudos do Letramento e destaca que a pluralidade cultural e linguística dos eventos de letramento já está incorporada na própria definição 
de letramento como prática social. Para ele, "Práticas de letramento parece-me, no momento, o conceito mais robusto dos vários conceitos de letramento que pesquisadores têm desenvolvido" (p.21), (tradução nossa). O letramento como prática social já engloba as várias culturas e diferentes linguagens e modos de fazer uso da escrita.

Em texto posterior (2006, p. 466), Street argumenta ser mais adequado falar em "letramentos", já que o termo seria útil para expressar as diferentes formas como diferentes grupos sociais se apropriam e usam a escrita, conforme interesses e objetivos específicos. Não seria produtivo, segundo o autor, a elaboração de grandes generalizações sobre os significados dos usos da escrita, uma vez que os grupos sociais se apropriam da escrita de maneiras particulares, próprias.

Neste artigo, adotamos a proposição de letramento como prática social (discutida na seção anterior). É considerado contexto multilíngue todo contexto em que se fala uma ou mais línguas, ou mais de uma variante de uma mesma língua (MARTIN-JONES; JONES, 2000). O que caracteriza o contexto como multilíngue não é o número de falantes daquelas línguas ou variedades, mas sim o ato social do uso dessas línguas e variedades. Ou melhor, o que caracteriza o multilinguismo é a questão social e não individual (MARTIN-JONES; JONES, 2000, STREET; LEFSTEIN, 2007, WEI, 2008).

\section{EVENTOS DE LETRAMENTO RELIGIOSOS}

Os Novos Estudos de Letramento propõem, além de estudos situados da sala de aula, estudos de outros contextos, os quais podem contribuir para ler as práticas de letramento escolarizadas (BAYNHAM, 2004).

Alguns estudos, como de Tusting (2000), são cruciais para a compreensão dos eventos de letramento religiosos que acontecem nas duas comunidades, lócus de pesquisa. Ele mostra, a partir de uma análise das práticas em torno de folhetos paroquiais de uma Igreja Católica, que o letramento em eventos sincronizados no tempo atinge metas sociais de manutenção da identidade comunitária tanto em nível local, sincronizando as atividades da comunidade paroquial, como no nível global, através da disseminação do letramento pela voz institucional da Igreja Católica. Nesse caso, as pessoas não se engajam com a discussão do conteúdo do texto escrito em si, mas com o ritual, o que significa que em situações multilíngues não necessariamente as pessoas precisam dominar a língua na qual foi produzido o texto escrito.

Nesse sentido, Poveda et al (2005), estudando o letramento em eventos religiosos em uma comunidade de ciganos, observou que a comunidade cigana, que até então era vista como uma comunidade de tradição oral, também tinha práticas em torno do texto escrito. A partir desse resultado, ele destaca a relevância de estudos mais situados nas práticas de letramento da comunidade cigana.

No Brasil, ainda há poucos estudos com enfoque nos eventos e práticas de letramento religiosos. Dentre os trabalhos que abordam as práticas religiosas, Duarte (2008) enfocou a preservação da identidade sociocultural por meio de práticas discursivoreligiosas em contextos rurais. Ela observou a prática religiosa do terço, como gênero discursivo, e percebeu que as estruturas linguísticas desse gênero representam uma 
prática social importante para a constituição da identidade social dos grupos analisados; na prática de terços cantados eram recitadas palavras tradicionais em latim que os rezadores reinterpretam de acordo com a fonologia do dialeto rural local.

Mezavila (2008) articulou a história, a religião e a língua em uma comunidade Católica ucraniana, da região Oeste do Paraná e observou que a Igreja Católica Ucraniana de rito bizantino ucraniano permanece e contribui para a manutenção e resgate da língua e da cultura na comunidade.

Considerando, assim, os estudos já realizados e a complexidade descrita, presente nos eventos de letramento religiosos, e a sua articulação com as relações sociais mais amplas, passamos, na próxima seção, à descrição dos eventos religiosos presentes nas duas comunidades.

\section{A CONSTRUÇÃO SOCIAL DE LETRAMENTO}

Nesta seção, descrevemos alguns eventos religiosos em duas comunidades: o município de São Mateus, no oeste paranaense, e outra comunidade (município) do sudeste paranaense - São Josafat. Os dados analisados são resultantes de duas pesquisas do tipo etnográfico. Não são trabalhos etnográficos propriamente ditos, pois nas duas comunidades não foi realizado um trabalho de campo observacional intenso e de longo prazo. Os trabalhos são qualitativos interpretativos que seguiram princípios e adotaram procedimentos desse tipo de pesquisa. Pelo fato de as pesquisadoras terem estudado comunidades familiares, o princípio da reflexividade e do estranhamento foram de suma relevância para os processos interpretativos (ERICKSON, 1989). Em termos de procedimentos, na comunidade São Mateus, o trabalho de campo foi realizado de fevereiro de 2001 a maio de 2001. Os instrumentos utilizados durante a observação participante foram: diário de campo, entrevistas semi-estruturadas, coleta de documentos e gravação em áudio e vídeo. Os registros obtidos por meio desses diferentes instrumentos de pesquisa foram indexados, formando um corpo de dados sistemático. Na comunidade São Josafat, o trabalho de campo foi realizado em 2009, por um período de três meses e vinte dias. Nesse período, foi realizada uma observação participante intensa e foram adotados os seguintes instrumentos de pesquisa: diário de campo, entrevistas semi-estruturadas, gravações em áudio e vídeo e coleta de materiais escritos.

\subsection{São Mateus}

Este município foi colonizado na década de 60 por descendentes de alemães. A maioria das pessoas do município professa a religião católica e os eventos de letramento (BARTON, 2007) que acontecem com maior frequência são dependentes da Igreja Católica. O culto dominical e a catequese, para crianças e adolescentes, são eventos religiosos semanais. Considerando que a maioria das pessoas são membros da paróquia católica participa, em princípio, desses eventos.

De acordo com o Projeto Político-Pedagógico da escola-núcleo João Dias, uma das seis escolas municipais na qual Jung $(2003,2009)$ realizou sua pesquisa para o 
doutoramento, 103 famílias que têm alunos na escola em que se deu o estudo são católicas, quatro são evangélicas pentecostais e duas famílias não responderam ao questionário de levantamento. Esse dado estatístico tem respaldo na própria colonização do município, pois as terras na área colonizada sob bases cooperativistas foram oferecidas a compradores de descendência alemã e de religião católica.

Os dados mostram que a religiosidade tem um papel crucial na construção e na manutenção de uma identidade local em dois sentidos, conforme veremos na descrição a seguir dos eventos religiosos que acontecem na comunidade: $1^{\circ}$ ) pelos modos de participação nos eventos de letramento que a Igreja propõe e $2^{\circ}$ ) pela orientação cristã que oferece. Essa orientação é dada por um representante da Igreja, no papel de ministro, catequista e, principalmente, pelo padre, que assume a voz institucional da Igreja, respaldada no texto escrito "sagrado".

O culto, o evento religioso mais frequente na Igreja Católica e na comunidade, consiste da leitura do folheto Culto Dominical, produzido por uma editora que tradicionalmente publica textos católicos. Esse folheto, de quatro páginas, contém as leituras litúrgicas de cada domingo, uma proposta de reflexão, cantos do hinário litúrgico da CNBB e artigo com o tema do dia ou acontecimento eclesial.

A leitura do folheto, que apresenta texto escrito essencialmente em português, é feita pelo ministro da eucaristia e por uma equipe de liturgia, que o lêem, conforme a sua organização. Membros da comunidade, que fazem parte de uma das equipes de liturgia, assumem o papel de leitor 1, leitor 2 etc., e o ministro da eucaristia assume o papel de dirigente. Além disso, há uma pessoa diferente para ler a primeira e a segunda leituras, que são dois textos bíblicos, um do Antigo Testamento e outro do Novo Testamento. A assembléia participa, conforme a indicação todos no próprio folheto, assim como o faz no momento dos cantos.

Não acontecem inversões na leitura do folheto, e os comentários e participações espontâneas são raríssimas, uma vez que as práticas de letramento nesse contexto estão convencionadas a um ritual. No caso dos comentários, somente o ministro tem autorização para fazê-los, o que ocorre raramente nos cultos que acontecem na igreja da Linha Santa ${ }^{2}$ Clara, por exemplo. Os comentários espontâneos parecem ser vistos pelas pessoas como uma lição de moral do ministro, que é um de seus vizinhos. Quando uma pessoa dessa comunidade rural que estuda fora retorna para visitar os familiares, a equipe de liturgia faz questão de chamá-la para ler. Dificilmente, entretanto, o responsável pela liturgia convida essa pessoa para fazer algum comentário espontâneo. Até mesmo no caso de pessoas que saíram da comunidade e que são irmãs ou irmãos religiosos, quando retornam e são chamados para comentar "as leituras", os residentes e membros permanentes ficam impacientes, evidenciando seu desconforto com isso.

As pessoas revelam-se incomodadas, ainda, quando a ordem do folheto é mudada. A participação espontânea da assembléia é solicitada, algumas vezes, pelo ministro no momento de pedidos ou preces, conforme o folheto. Quando isso acontece, a prece do ministro e de um líder da Linha Santa Clara, por exemplo, costuma ser intercalada por longos silêncios. Um dos motivos para não alterar a ordem do folheto é a presença de

\footnotetext{
${ }^{2}$ Linha Santa Clara é uma das trinta comunidades rurais do município São Mateus.
} 
pessoas de mais idade que, embora sejam monolíngues em alemão, participam do evento. A sequência rígida das partes constituintes do evento, conforme prédeterminado pela tradição, permite que todos participem adequadamente. Nesse sentido, esse evento de letramento serve para manter uma identidade religiosa local de três modos: $1^{\circ}$ ) pelo uso do letramento nesse evento sincronizado no tempo, corroborando a tese de Tusting (2000); $2^{\circ}$ ) porque constroi modos culturais de fazer uso da leitura e escrita, logo, práticas de letramento, os quais permitem identificar quem não é um membro da comunidade; e $3^{\circ}$ ) porque garante a disseminação do letramento pela voz institucional da Igreja católica (TUSTING, 2000).

Quando, porventura, a sequência do culto é modificada ou um novo elemento é introduzido, podem surgir impasses.

Em um dos cultos de que participei [JUNG, 2003] na Linha Santa Clara, durante a primeira fase de trabalho de campo (março de 2001), antes de sentar-me, fui buscar a folha de canto, que, algumas vezes, é uma folha ou um livro à parte. Como peguei mais de uma folha, passei uma para minha mãe, algumas para as pessoas que estavam no banco de trás e uma para a senhora que estava ao meu lado. Essa minha atitude criou um momento desconfortável, pois a senhora ao lado, no momento de cantar, esquecia de sentar, desrespeitando uma das formas de participação do evento, para procurar o canto. Quando o culto terminou, no caminho de casa, minha mãe comentou: "Du hecht theve net de Melita ein Plot gebe. Die kann net lese und hat sich gans atrapalhiat. Die hat ich tenge niks von de Ondach - você não deveria ter passado aquela folha de cantos para a Melita. Ela não sabe ler e se atrapalhou toda. Provavelmente, não teve nada do culto (Diário de campo - 04/03/01).

Essa é uma evidência de que as pessoas da comunidade aprenderam a participar do evento de letramento culto. As pessoas monolíngues em alemão garantem a sua participação através de respostas prontas e observando devidamente as formas de participação no evento e no domínio da Igreja. O modo de vestir, de sentar no lado destinado para os homens e para as mulheres, de sentar, ajoelhar e ficar em pé no momento certo, a devida tomada de turno, conforme o folheto, a melodia dos cantos, os silêncios, evitando barulhos como choro de crianças, batida de bancos no momento de ajoelhar-se, barulho de tosse, também garantem a correta participação das pessoas no culto.

Um outro fato que aconteceu na Linha Santa Clara mais ou menos na metade do culto, no momento da consagração da comunhão, mostrou como a comunidade rural reage quando alguém não participa do culto conforme o esperado. Uma vez que as pessoas precisam baixar uma parte do banco à sua frente, para ajoelhar-se sobre essa parte e, depois do ritual, erguê-la novamente, alguns acabavam fazendo barulho durante essa movimentação. Diante disso, o representante do Conselho Comunitário Pastoral (CCP), que tem como função zelar pelas normas apresentadas pelo padre, ao final de um culto, fez o seguinte comentário:

Gostaríamos de solicitar que as pessoas cuidassem mais ao baixar e erguer o banco na hora da comunhão. É preciso ser cuidadoso, 
evitando essa barulheira que geralmente acontece. É preciso segurar o banco até o chão ou até estar no lugar. Precisamos evitar essa bateção que costuma acontecer (Diário de campo - 18/02/01).

Antes de uma reprimenda pública, entretanto, os participantes que não identificarem e observarem essas normas são motivo de comentários na comunidade. A mãe ou o pai que não cuidarem do filho que eventualmente acaba por derrubar um banco são criticados como pais relapsos. Os demais membros controlam as formas de participação social desse domínio. O dado de uma senhora, com criança pequena, que deixou de frequentar a igreja nos primeiros meses de vida da criança por medo de que a criança chorasse na igreja, atrapalhando as outras pessoas, dimensiona a importância dessas regras. Essa atitude é incentivada por sua sogra, que é uma das colonizadoras da Linha Santa Clara, e destaca:

"das is besser wenn das werglich de hemm bleibt. wall wenn de nene brille dud dann hat das niks von der ondach un atrapalhiert noch die andre lait” - é melhor mesmo que ela fique em casa, pois se o nenê chorar, além de ela não ter nada do culto, vai atrapalhar as outras pessoas (Diário de campo - 25/02/01).

Para ser um membro pleno da comunidade, é preciso participar dos cultos e saber participar. A participação das pessoas, as formas de participação e os modos de se apresentar na igreja garantem que alguém seja ou não respeitado na comunidade como membro efetivo dela. Os participantes relaxam um pouco, quase no final do culto, quando um senhor lê os avisos. Trata-se sempre da mesma pessoa que, diferentemente da equipe de liturgia, fica no meio do povo. Para ler os avisos, simplesmente fica em pé, lendo os comunicados de reuniões na comunidade e na zona urbana, ou seja, é o momento de informar a comunidade. Algumas vezes, esse senhor lê o aviso e o comenta, logo depois, em brasileiro ou alemão. As pessoas, quando reagem diante de um aviso, também costumam cochichar em alemão. Antes do culto e depois, ainda dentro da igreja, as conversas costumam ser em alemão.

A participação da equipe de liturgia e do ministro nos eventos de letramento nesse ritual parece ser medida em termos de leitura rápida, sem gaguejar, e com um tom de voz elevado. O seu modo de vestir e a sua postura, uma vez que ficam de frente para a platéia, também são avaliados em termos de competência.

Assim sendo, o evento culto parece contribuir para fortalecer uma identidade local pelo fato de ser um ritual (BARTON, 2007) em que as pessoas estão sincronizadas por um período de tempo co-sustentando um ser divino. Não há uma construção conjunta de um sentido do texto escrito. O sentido é construído pelo padre ou ministro que assumem a voz institucional da Igreja para “orientar” as pessoas. Nesse último sentido, a Igreja parece ser um domínio que, através de rituais e dos eventos de letramento que os constituem, trabalha uma moral, que, nessa comunidade, é um dos traços da identidade religiosa, positivamente ratificada na interação.

Um dado que corrobora a asserção de que a Igreja é um domínio representativo na construção de uma moral é o fato de o próprio padre ou ministro, para assumir a voz institucional, precisar negociar uma imagem de si muito próxima àquela do Deus construído e sustentado pela comunidade. Quando algum fato afeta essa imagem, além 
de ser muito comentado na comunidade, isso pode ser levado para o Conselho Comunitário Pastoral cujos membros decidem as medidas a serem adotadas.

A presença do padre nas comunidades rurais é esporádica. Ele é o representante da Igreja católica em nível de município e, por isso, parece assumir com bastante autoridade a voz institucional da Igreja para orientar os membros da comunidade.

No município, o padre, em algumas ocasiões, é a autoridade máxima. Ele não somente está autorizado a mudar a ordem de uma missa, de um culto, mas pode mudar, como o fez recentemente, a forma de organização da paróquia, unidade da Igreja católica no município, facultando-lhe uma interferência mais efetiva na vida social. Ele impediu, por exemplo, que as lanchonetes da cidade realizassem eventos musicais durante 0 período da quaresma, além do que proibiu o uso de roupas decotadas pelas pessoas que participam da liturgia, enfim, ele, de alguma forma, afetou a vida da grande maioria das pessoas de São Mateus. Através da voz da Igreja, via texto escrito em português, o padre contribui para a manutenção de uma identidade local, incluindo quem participa da Igreja e excluindo quem não participa dela, assim como quem não observa as formas de participação e o que está escrito no "livro sagrado".

Nesse sentido, o texto escrito é apresentado pelo padre como sagrado, ou melhor, o texto escrito legitima a autoridade clerical, que tem respaldo na palavra escrita. Para essa orientação ser sustentada pelos co-participantes, o padre mostrou, em uma missa, uma preocupação em simplificar o texto escrito em português. Ele solicitou a adesão a um abaixo-assinado e, para tanto, ele explicou tratar-se de um documento que será enviado ao Governador do Paraná, solicitando o retorno das aulas de Ensino Religioso nas escolas estaduais do Paraná. O padre mostrou, com detalhes, como as pessoas deveriam assinar. Disse ele:

Na primeira parte, vocês escrevam o nome, em letra de forma, depois o número da identidade e, por último, a assinatura. Por favor, só assine quem estiver com a identidade aí, porque senão depois esquece de anotar o número e aí invalida a assinatura (Diário de campo 09/05/01).

O padre explicou com significativo grau de detalhamento como as pessoas deveriam proceder para assinar o documento. Esse parece ser um indício de que o padre, em razão do vínculo que estabelece com a comunidade, sabe que algumas pessoas têm pouco conhecimento do português escrito, por isso, para que a sua voz seja ouvida, ele precisa explicar com maior detalhamento o texto escrito.

Um outro evento religioso que tem mais ou menos o mesmo formato que o culto e a missa é a catequese. Esse evento acontece semanalmente e dele participam as crianças com mais de nove anos que se preparam para a Primeira Comunhão e os adolescentes que se preparam para o Crisma. As pessoas da própria comunidade voluntariamente prestam serviço à catequese. Em geral, há mais catequistas mulheres que homens. Elas são preparadas em alguns encontros na paróquia. Cada catequista trabalha com um grupo de crianças e/ou adolescentes, separados por faixa etária. Há a adoção de um livro, pré-definido pela paróquia, o qual norteia o trabalho. Em geral, esse evento é muito semelhante ao culto, uma vez que é constituído por leitura da lição do dia, 
mudando somente a oração e/ou o canto inicial e final. As pessoas mais velhas costumam criticar o que é trabalhado nesse evento. Segundo elas, as crianças e os adolescentes não aprendem os conceitos e as orações básicas da religião católica. Uma senhora comenta com outra o que ambas presenciaram no batizado que se seguiu à missa em Linha Santa Clara:

Nossa, eu não sabia mais aonde enfiar a cara, pois o padre perguntava o que os pais queriam, e eles respondiam que queriam saúde, amor e não respondiam que tinham vindo para buscar o batismo da filha. Eu já falei para a minha filha, no dia que você batizar o seu filho e o padre perguntar isso e você não souber responder, eu levanto do meu banco e vou lhe dar um tapa (Diário de campo - 07/03/01).

O que essa fala evidencia é que, na catequese, assim como no culto, as pessoas coordenam suas ações pelas formas de participação social, e o texto escrito serve para legitimar a voz da Igreja. Se, por um lado, isso é visto como o caminho de usar a leitura e a escrita, por outro, as crianças e os adolescentes estão deixando de aprender conceitos básicos que comprometem, conforme destacou a mãe, sua identidade religiosa local.

Em síntese, os eventos de letramento promovidos pela Igreja Católica podem ser definidos como práticas de letramento, uma vez que são eventos regulares na comunidade e contribuem para a construção de padrões culturais de uso da leitura e escrita (BARTON, 1994). O culto, além de ser a prática de letramento mais regular, é também a prática mais importante, uma vez que contribui para a manutenção de uma identidade religiosa local. Em outras palavras, os membros das comunidades rurais participam das práticas da Igreja, nos finais de semana, porque ali se sentem um grupo, um nós. A participação parece lhes dar condições de ser um membro pleno do grupo, pois, além da sincronia de formas de participação social, ali assumiriam os valores morais necessários para serem cidadãos honestos. Aquele que não participa dessas práticas é excluído também de encontros, como jogos de baralho entre as mulheres e rodas de chimarrão, agendados após do culto. Além disso, tais membros da comunidade não ficam sabendo das reuniões de interesse comunitário, das quais deixarão de participar. Como consequência, deixarão de ser, paulatinamente, membros da comunidade local.

Assim, no culto, os membros das comunidades rurais têm uma motivação para o encontro. Essa prática, bem como a missa e a catequese, referenda os valores necessários para que alguém seja um membro da comunidade legítima, autorizada, hegemônica. Esses valores são encontrados na leitura do texto escrito em português e confirmados por pessoas autorizadas, como o ministro, os catequistas, o senhor que lê os avisos e, principalmente, pelo padre.

\subsection{São Josafat}

São Josafat é um município localizado no sudeste do Paraná, colonizado por imigrantes, em sua maioria ucranianos, além de poloneses, alemães e italianos. A colonização do município iniciou com a imigração ucraniana para o Paraná no final do século XIX, que aconteceu em três etapas e por razões diferenciadas. 
A primeira etapa data dos fins do século XIX, quando os lavradores da Galícia e Bucovina, sob o domínio da Áustria, com problema de superpopulação, fraca industrialização e más condições econômicas, procuraram outros países. O apogeu dessa etapa ocorreu, no entanto, no início do ano de 1895, quando aproximadamente quinze mil pessoas vieram da Ucrânia Ocidental, fixando-se principalmente na comunidade São Josafat (MEZAVILA, 2007), no Paraná. A segunda etapa da imigração ucraniana decorreu da Primeira Guerra Mundial e a terceira etapa ocorreu após a Segunda Guerra Mundial, quando mais de duzentos mil ucranianos se deslocaram para vários países.

Atualmente o município São Josafat possui uma população de 50.614 habitantes, segundo dados do IBGE (2008). A principal fonte de renda no município é proveniente da agricultura, da fumicultura (produção do fumo) e de olarias; atualmente também tem se destacado o turismo devido a questões ecológicas e aos costumes e às construções ucranianas.

Em São Josafat, os eventos da Igreja Católica acontecem em dois ritos, o latino e o ucraniano, os quais são realizados em espaços físicos diferentes. Isso não ocorre nas comunidades rurais, nas quais geralmente os eventos de cada rito são realizados no mesmo espaço físico, no entanto em dias diferentes.

A diferenciação da Igreja Católica em ritos começou em 1054, quando o Cristianismo tradicional dividiu-se entre orientais ou bizantinos, ocidentais e latinos que formam a Igreja Católica (KINDRA, 2009). A Igreja Católica Ucraniana é constituinte do rito Oriental Bizantino, no Brasil definida como Igreja Ucraíno-Católica e, na Ucrânia, como Igreja Greco-Católica Ucraniana. A vinda da Igreja Greco-Católica Ucraniana ou Ucraíno-Católica para o Brasil se deu pela imigração de ucranianos, principalmente para a região Sul. A Igreja Católica Romana de rito latino e a Igreja Bizantina UcraínoCatólica professam a mesma doutrina e seguem o Vaticano, mas possuem particularidades histórico-culturais, uma tradição litúrgica e ritual diferenciadas. A Igreja Católica de Rito Ucraniano em todo o mundo é dirigida pelo Cardeal Dom Lubomyr Husar, em Kiev, na Ucrânia, e segue as orientações da Igreja de Rito Oriental no que diz respeito a sua Liturgia, disciplina eclesiástica, orientações pastorais e doutrinárias, não somente na Ucrânia, mas também nos países de imigração ucraniana.

Em termos de letramento, foram reconhecidos alguns eventos religiosos, como missa, novena, grupos de oração e catequese. Além disso, na Igreja de rito ucraniano, há aulas de língua e cultura em uma escola paroquial mantida pela Igreja Ucraíno-Católica da comunidade. Nas missas e novenas, há uma sequência de leituras e orações a serem realizadas. Assim como na comunidade São Mateus, há papéis sociais a serem desempenhados, e as pessoas participantes da missa e do culto procuram desempenhar seus papéis sociais, ou seja, os ministros e as pessoas da comunidade responsáveis por leitura naquele dia agem conforme o papel que lhes foi delegado, e os demais participantes co-sustentam esses papéis. Sendo assim, além de o texto escrito religioso garantir a autoridade do padre, acaba possibilitando também a manutenção desse papel para algumas pessoas da comunidade. Desse modo, evidencia-se que participar de eventos de letramento na igreja, sobretudo com papéis sociais de maior autoridade, consiste em capital simbólico na comunidade (BOURDIEU, 1998). Participar adequadamente dos rituais religiosos, saber os momentos de tomar o turno, levantar, 
sentar, ajoelhar-se, garante também o reconhecimento das pessoas como membro do grupo, ou melhor, como membro competente do grupo.

Essas ações e modos de participação caracterizam alguns rituais religiosos e estão relacionados aos eventos e práticas de letramento, pois no decorrer de todo ritual, o texto escrito do folheto, do livro de cantos, do livro de novena, subsidia os modos de participação e de interação com o texto escrito. Por exemplo, durante a leitura do evangelho, um evento de letramento típico das missas católicas, os participantes devem adotar determinados modos de participação, inicialmente devem tomar o turno em coro em resposta à leitura do padre e depois acompanhar em pé a leitura do texto, feita pelo padre. Se um participante desse evento não toma o turno no momento requerido ou não acompanha a leitura em pé, ele pode estar acompanhando a leitura, mas seu modo de participação não é aquele sócio-historicamente construído, o que pode revelar que ele não é um membro do grupo católico, ou, caso seja, não é um membro competente.

Os modos regulares de como devem ser as ações das pessoas em muitos eventos de letramento, em contextos particulares, acontecem porque os domínios são contextos estruturados e padronizados. Atividades dentro desses domínios não são acidentais ou aleatoriamente variadas: existe uma configuração específica de práticas de letramento (BARTON; HAMILTON; IVANIC, 2000). Desse modo, a configuração das práticas de letramento nos eventos religiosos é regulada por convenções que constituem esses ritos, os quais requerem modos de participação específicos e práticas regulares em torno do texto escrito.

Além dos modos de participação, a Igreja Católica tanto de rito latino como de rito ucraniano, contribui também para a disseminação de alguns valores que transcendem o modo de participar "corretamente" nos eventos e nas práticas regulares de letramento naquele contexto. Para ser um membro efetivo da comunidade, é preciso não só agir adequadamente no grupo, mas vestir-se "respeitosamente”. Giddens (2002) salienta que "[...] a roupa é um meio de auto-exibição, mas também se relaciona diretamente à ocultação/revelação a respeito das biografias pessoais - liga as convenções a aspectos básicos da identidade” (p.63). Nessa comunidade, a roupa, o modo de vestir-se, é determinante para a aceitação no grupo, para ser reconhecido como membro da comunidade. Há necessidade constante de fazer com que os membros do grupo sigam também essa convenção, por exemplo, na Igreja Católica latina há um cartaz em destaque com a ilustração de uma família com traços que dão ênfase para as roupas sem decotes e bem alinhadas seguida por uma frase "Vestir-se com pudor. Vestir-se como se veste a mãe do Senhor”. Na Igreja de rito ucraniano, há um panfleto que é distribuído para exame de consciência e também para preparação para a confissão, no qual há um item destinado para questões relacionadas ao modo de vestir-se, "Tenho me vestido de modo a chamar a atenção dos outros?”.

Quando, porventura, um membro não está vestido seguindo as convenções, com uma roupa curta ou decotada, ou muito apertada, os membros manifestam a nãoconcordância e a inadequação pelo olhar, por exemplo, ou seja, a expressão corporal é um aspecto central do que não pode ser dito com palavras (GIDDENS, 2002). Geralmente quando isso acontece, a pessoa que está burlando de certo modo essa convenção sabe que o está fazendo, pois também como membro do grupo aprendeu a 
tornar-se um membro competente, capaz de juntar-se aos outros em bases iguais na produção e reprodução de relações sociais (GIDDENS, 2002).

Nossa, você viu a cara que estavam olhando para nós lá atrás. Dos pés a cabeça. Mas eu não estou nem aí também, eu não ia voltar lá em casa só para trocar de roupa para ir ao rodeio depois. (Diário de Campo 19-04-2009)

Nesse excerto do diário de campo, três jovens estavam conversando sobre a postura de algumas pessoas, próximas a elas durante a missa. Essas jovens estavam com roupas apertadas, com decotes e maquiagem na missa de dez horas, no domingo. Embora sejam membros da Igreja Católica, essas jovens participam de outra comunidade de prática, fora do município, e demonstram não aceitar irrestritamente as convenções apregoadas pela maioria dos membros naquela comunidade.

Através desses modos e convenções solicitados para a participação dos eventos nas igrejas, a Igreja Católica contribui para a disseminação na comunidade de uma identidade local co-sustentada pelas vestimentas. Em outros domínios, a roupa também indicia pertencimento ao grupo.

Clara da $5^{\text {a }}$. série chegou e falou para a mãe que precisava fazer outra camiseta do colégio, pois uma das duas camisetas que usava para ir ao colégio não era camiseta, era babylook e o diretor havia solicitado que não era mais para vir de babylook, era para procurar providenciar outra camiseta, pois não seria permitido mais que as meninas viessem de babylook, pois algumas estavam ficando curtas. (Diário de campo 10-03-2009)

Dentre os eventos relacionados ao domínio (BARTON, 2007) da Igreja Católica ainda há a catequese, evento religioso, no qual os membros se tornam autorizados a receber certos sacramentos, como a Comunhão. Há uma diferenciação no tempo da catequese no rito latino e no rito ucraniano. No rito ucraniano, as pessoas recebem o sacramento da Crisma no momento do batismo, já no rito latino as pessoas fazem o Crisma depois da Primeira Comunhão, com mais dois anos de catequese. Na sequência, descrevemos os eventos de letramento da catequese de ambos os ritos.

Na catequese de rito católico, quem conduz os eventos é a catequista, geralmente uma pessoa da comunidade, membro da Igreja, que desempenha um papel instrucional no evento, que negocia um status não só hierárquico, co-sustentado por um rito religioso, mas co-sustentado por um papel de quem sabe.

Quando Ana pergunta quais os evangelhos que falam sobre a morte e ressurreição de Jesus, explicados por ela anteriormente, as crianças permanecem em silêncio. Ana pergunta novamente, após um tempo de silêncio, um menino toma o turno e diz que são os evangelhos de Mateus, Marcos e Lucas. Ana toma o turno novamente repetindo reposta de Felipe, ratificando-a como correta e complementando a resposta. "Isso, Mateus, Marcos, Lucas e João" (Diário de Campo, 27-04-2009). 
A catequese, embora seja proposta pela Igreja Católica, não acontece com uma regularidade fixa, seguindo um rito. O evento apresenta modos de participação também recorrentes nos rituais religiosos como, por exemplo, orações iniciais, cantos religiosos, práticas em torno de textos religiosos, no qual a catequista é quem assume o papel de maior autoridade institucional não só para conduzir o evento, mas também para apresentar as interpretações e leituras “corretas”. Além de assumir a voz de autoridade institucional da Igreja Católica, ela assume também o papel daquela que sabe e de quem ensina. Assim evidencia-se na catequese que, além das práticas trabalhadas em rituais religiosos, esse evento apresenta também características típicas de práticas escolares de letramento, reafirmando a proposição de Barton (2007) de que não há fronteiras entre os domínios de letramento, muitas práticas recorrentes em eventos de alguns domínios podem acontecer também em outros domínios.

Na comunidade São Josafat tem ainda uma escola paroquial, uma instituição mantida pela Igreja Católica Ucraniana, que tem como objetivo ensinar para as crianças a língua escrita e a cultura ucraniana. A escola desenvolve práticas de letramentos distintas dos eventos que acontecem na Igreja, mesmo que ainda tenha presente algumas práticas similares e regularidades nos modos de participação. Por exemplo, dentre as aulas oferecidas na escola paroquial, estão aulas de língua ucraniana, de bandura - um instrumento musical típico -, aulas de canto, de artesanato etc. A aula de língua ucraniana é ministrada por catequistas, mulheres de organização religiosa ucraniana, que se dedicam a professar a cultura e a religião católica ucraniana.

Na aula de língua ucraniana, há uma sequência que também apresenta características do domínio escolar (BARTON, 2007). A aula inicia com a oração em ucraniano e com o hino ucraniano; em seguida, a professora passa uma tarefa geralmente associada a estruturas linguísticas da língua ucraniana, como tradução, e depois uma tarefa de linguagem que envolve a cultura e a religião ucraniana, como cantos, música etc. O principal objetivo da escola na aula de língua é alfabetizar as crianças em ucraniano, torná-las proficientes na escrita ucraniana, buscando familiarizá-las principalmente com textos escritos religiosos.

Desse modo, o domínio da escrita padrão na língua ucraniana não é de acesso à maioria da população, geralmente é de uso de uma elite, constituída por religiosos, estudiosos da cultura, ou pessoas da comunidade que tiveram interesse, necessidade e possibilidade de adquirir esse sistema de escrita e desenvolvê-lo de modo funcional para que de fato pudessem fazer uso da escrita da língua ucraniana. A maioria da população fala a língua ucraniana, mas tem acesso e faz uso da escrita ucraniana somente em eventos relacionados à Igreja e em textos religiosos divulgadas pela Igreja. Essa iniciação ao domínio básico do sistema de escrita ucraniana se dá na catequese, na escola paroquial ou por um membro da família que já tem conhecimento, conforme evidencia um trecho de entrevista apresentado a seguir:

Jane: e em relação (.) assim (.) na comunidade (.) mais pessoas costumam (.) usam falar em ucraniano?

Marcos: é as pessoas que participam lá da igreja do rito ucraniano (.) todas né.

Jane: uhum.

Marcos: conversam em ucraniano (.) tudo mais. 
Jane: e com textos escritos em língua ucraniana (.) vocês tem contato em que lugares (.) que tipo de textos (.) ou não tem contato.

Marcos: é a gente tem mais contato é na igreja (.) porque na igreja ucraniana (.) daí tudo os livros os folhetos é em ucraniano (.) daí a gente acompanha tudo em ucraniano.

Jane: uhum (.) e você consegue ler em ucraniano.

Marcos: consigo (.) pouco, mas consigo. (Excerto de entrevista realizada em 07/05/2009)

Esse dado mostra que os eventos de letramento da Igreja Católica de rito ucraniano contribuem para a manutenção e para o desenvolvimento de práticas de letramento em torno da língua ucraniana escrita. Nesse sentido, evidenciou-se que a Igreja tem papel preponderante na manutenção e no desenvolvimento de práticas de letramento em torno da escrita ucraniana. A Igreja nessa comunidade não é somente cenário para práticas de letramento em torno da escrita ucraniana, mas também responsável pela maioria dos textos nesta língua que circulam no município, uma vez que a mesma possui uma gráfica para produção de matérias escritos na língua. São exemplos de textos produzidos em língua ucraniana, ou em partes na língua ucraniana e outra parte na língua portuguesa, revistas de orações, folhetos e jornal informativo. Alguns materiais escritos são produzidos também em língua portuguesa, como é o caso do jornal informativo para prestação de contas para a comunidade. Segundo dados de Mezavila (2007), em comunidade de imigração ucraniana no oeste paranaense, isto acontece para que todos os membros possam entender o texto, uma vez que nem todos têm conhecimento da língua escrita ucraniana, ou seja, como membros precisam conhecer dados importantes da Igreja.

Em outubro de 1998 foi apresentada à comunidade católica ucraniana brasileira a tradução para o português da liturgia realizada pela Comissão Eparquial de Liturgia, que traz a assinatura do então Bispo Eparca Dom Efraim Krevey. De acordo com essa autoridade, a medida viria favorecer a urgência em cativar as novas gerações de descendentes de ucranianos para a Igreja (BABAR, 2008).

Mezavila (2007) destaca que, atualmente, a liturgia do rito oriental pode ser celebrada na língua vernácula de cada país, onde haja fiéis desse rito, mas que, no Brasil, a liturgia continua sendo celebrada em ucraniano, sendo apenas celebrada em língua portuguesa naqueles locais, onde as circunstâncias exigem. Isso, no entanto, precisa de uma autorização expressa do bispo-eparca, que raramente é solicitada. A eparquia de Curitiba, que coordena a Igreja Católica ucraniana no Brasil, recomenda que o rito seja realizado na língua de domínio da comunidade; por exemplo, onde os membros entendem a língua ucraniana, celebra-se a liturgia no idioma ucraniano; onde já houve uma intensa assimilação à língua portuguesa e as pessoas já não entendem a língua ucraniana, as celebrações podem ser realizadas em língua portuguesa, porém sempre no rito Oriental Bizantino.

Assim como na comunidade pesquisada por Mezavila (2007), na comunidade São Josafat, o rito oriental bizantino continua sendo realizado na língua ucraniana, e duas vezes por semana, em determinados horários, realizado em português, mas de acordo com o rito oriental bizantino. 
Desse modo, as práticas de letramento da Igreja Bizantina Ucraíno-Católica contribuem com a manutenção de uma identidade ucraniana. Nessa comunidade, assim como na comunidade pesquisada por Mezavila (2007) no oeste do Paraná, a língua ucraniana usada nos eventos associados à Igreja é de suma importância para a manutenção não só da língua, mas da cultura ucraniana.

Em síntese, a Igreja Católica de rito-ucraniano e a Igreja Católica de rito latino contribuem para co-sustentar modos de participação nos eventos de letramento. Em ambas as Igrejas, há uma preocupação com a manutenção de modos aceitáveis de participação na comunidade. Esses modos de participação vão desde tomar o turno em momento relevante, sentar-se ou levantar-se, não fazer barulhos inapropriados, até ao modo de vestir-se. Evidenciamos, assim que, na comunidade São Josafat, a Igreja Católica de rito latino e a Igreja Católica de rito ucraniano contribuem para a sustentação de uma identidade local, através dos modos de participação nos eventos religiosos. A Igreja de rito ucraniano, além disso, procura em práticas de letramento religiosas ensinar traços da língua e da cultura ucranianas.

\section{CONSIDERAÇÕES FINAIS}

O presente artigo teve como objetivo descrever e analisar práticas sociais letradas em eventos de letramento religiosos em duas comunidades multilíngues do Paraná. Os dados mostram que na comunidade de São Mateus, colonizada por descendentes de alemães em sua maioria filhos da segunda geração nascida no Brasil que migraram do noroeste do Rio Grande do Sul para o oeste do Paraná, as pessoas interagem somente com o texto escrito em português e crucialmente pelas práticas de letramento associadas à Igreja Católica. Essas práticas têm um papel crucial na construção e na manutenção de uma identidade local em dois sentidos: $1^{\circ}$ ) pelos modos de participação nos eventos de letramento que a Igreja propõe e $2^{\circ}$ ) pela orientação cristã que oferece. Além disso, elas estão articuladas com a construção identitária presente na comunidade e contribuem em alguma medida para a manutenção de uma identidade étnico-alemã, assumida especialmente pelos homens (JUNG, 2009).

Na comunidade de São Josafat, o letramento acontece não só em termos de práticas em torno da escrita em língua portuguesa, mas também na língua ucraniana, a qual desempenha um papel crucial na manutenção da língua e da cultura ucranianas. Nessa comunidade, do mesmo modo que nas comunidades ciganas, estudadas por Poveda et al (2005) em que os movimentos associados à Igreja Evangelista são vistos como cruciais para o desenvolvimento cultural cigano e manutenção da identidade do grupo, a Igreja contribui para a manutenção da língua e cultura do grupo.

A participação na prática da catequese é, no entanto, reduzida; participam dela principalmente descendentes de imigrantes ucranianos que têm algum objetivo com a aprendizagem da língua escrita e da cultura ucranianas. Trata-se de um processo de manutenção de uma identidade ucraniana, elitizada, que parece ser diferente de uma identidade ucraniana brasileira. Enquanto o ucraniano falado pela maioria na comunidade está associado, assim como na comunidade São Mateus, ao meio rural, a Igreja Bizantina Ucraíno-Católica procura contribuir para a manutenção do ucraniano 
culto, da escrita e cultura ucraniana. A implicação desses dados para os eventos escolares está em análise (SEMECHECHEM, em andamento).

Esses dados apontam, enfim, para a relevância teórico-metodológica da etnografia nos estudos de letramento, especialmente em contextos multilíngues e multiculturais, além da importância de estudos situados de eventos e práticas de letramento em contextos não-escolarizados, servindo para minimizar a invisibilidade desse letramento.

\section{REFERÊNCIAS}

BABAR, Lara Janek. Características, transformações e adaptações da música religiosa ucraniana no Paraná. Dissertação de Mestrado em Música. Universidade Federal do Paraná, Curitiba, 2008.

BARTON, D; HAMILTON, M; IVANIC, R (Orgs) Situated literacies: reading and writing in context. Londres e Nova York: Routledge, 2000.

BARTON, David. Literacy: an introduction to the ecology of writing language. 2. ed. Oxford: Blackweel, 2007.

BAYNHAM, Mike. Ethnographies of Literacy: Introduction. Language and Education. Leeds, UK, University of Leeds, School of Education. v. 18, n. 4, 2004. pp. 285-290.

BOURDIEU, P. A economia das trocas linguísticas: o que falar quer dizer. Tradução de S. Miceli. 2. ed. São Paulo: Editora da Universidade de São Paulo, 1998.

DUARTE, Aline do nascimento. A preservação da identidade sociocultural por meio de práticas discursivo-religiosas em contextos rurais. (Dissertação de Mestrado em Linguística) Universidade de Brasília, Brasília, 2008.

ERICKSON, F. Metodos cualitativos de investigacion sobre la ensinanza. In: WITTROCK, M. C. (Org.). La investigación de la enseñanza, II: metodos cualitativos y de observación. Barcelona: Paidos, 1989. p. 195-301.

GEE, James. Social Linguistics and literacies: ideology in discourse. London: The Falmer Press, 1990.

GIDDENS, Anthony. Modernidade e identidade. Tradução Plínio Dentzien. Rio de Janeiro: Jorge Zahar Editor, 2002.

HAMILTON, M. Expanding the new literacy studies: using photographs to explore literacy as social practice. In: BARTON, D., HAMILTON, M., IVANIC, R. (Orgs.). Situated literacies: reading and writing in context. Londres e Nova York: Routledge, 2000. p. 16-34.

HEATH, S. B. Ways with words. Cambridge: Cambridge University Press, 1983. 
HORNBERGER, N. H. Criando Contextos Eficazes de Aprendizagem para o Letramento Bilíngue. Tradução de Ana Antônia de Assis-Peterson e Maria Inês Pagliari Cox. In: COX, M.I.P. e ASSIS-PETERSON, A.A. (Orgs.). Cenas de Sala de Aula. Campinas, SP: Mercado de Letras. 2001. p. 23-50.

Introduction. In:

(Ed.). Continua of biliteracy: an ecological framework for educational policy, research, and practice in multilingual settings. Clevedon: Multilingual Matters Ltd, 2003a. p. xii-xxiii.

Continua of Biliteracy. In: (Ed.). Continua of biliteracy: an ecological framework for educational policy, research, and practice in multilingual settings. Clevedon: Multilingual Matters Ltd 2003b. pp. 3-34

; SKILTON-SYLVESTER E. Revisiting the continua of biliteracy: international and critical perspectives. In: HORNBERGER, N. H. (Ed.). Continua of biliteracy: an ecological framework for educational policy, research, and practice in multilingual settings. Clevedon: Multilingual Matters Ltd, 2003c. pp. 35-67.

HORNBERGER, N. H. Voz y Biliteracidad en la Revitalización de Lenguas Indígenas: Prácticas Contenciosas en Contextos Quechua, Guarani y Maori. QINASAY Revista e Educación Intercultural Bilíngue. N.3. Cochabamba, Bolívia: PROEIB Andes/GTZ. 2005. p. 119-136.

JUNG. N. M. Identidades sociais na escola: gênero, etnicidade, língua e as práticas de letramento em uma comunidade rural multilíngue. Tese de doutorado. Universidade Federal do Rio Grande do Sul. Porto Alegre, 2003.

A (re)produção de identidades sociais na comunidade e na escola. Ponta Grossa/PR: Editora UEPG, 2009.

KINDRA, Ivan. O rito ucraniano e as Igrejas orientais. Representação Central Ucraniano-Brasileira. Disponível em http:// www.rcub.com.br. Acesso 13 de novembro de 2009.

MARTIN-JONES, Marilyn; JONES, Kathryn (Orgs). Multilingual literacies: reading and writing different worlds. Jonh Benjamins. 2000. pp. 285-290

MARTIN-JONES, Marilyn. New times, new literacies: implication for the design of bilingual Pedagogy. Caderno de Resumos do III Bilinglatam: III Simpósio sobre bilinguismo, Educação Bilíngue e Cidadania. SP: PUC, 2009. p. 34-36.

MEZAVILA, Albertina. Ucranianos em Cascavel: a História, a Religião e a Língua. Dissertação de Mestrado em Letras, Linguagem e Sociedade. Universidade Estadual do Oeste do Paraná, Cascavel, 2007.

POVEDA, David; CANO, Ana; PALOMARES-VALERA, Manuel. Religious genres, entextualization and literacy in Gitano children. Language in Society. United States of America, 2005, n. 34. p.87-115. 
ROSOWSKY, Andrey. Heavenly readings: Liturgical literacy in a multilingual context. Multilingual Matters, 2008.

SEMECHECHEM, Jakeline. Interação e identidades em eventos de letramento escolares em contexto multilíngue/multicultural no sudeste do Paraná. Dissertação de Mestrado em Letras. Universidade Estadual de Maringá/PR, Maringá, (em andamento).

STREET, Brian. Literacy in theory and practice. Cambridge: Cambridge University Press, 1984.

. Cross - Cultural approaches to literacy. Cambridge: University press, 1993.

. Social literacies: critical approaches to literacy in development: ethnographic perspectives. Londres \& New York: Longman, 1995.

. Literacies events and literacy practices: theory and practice in the New Literacy Studies. In: MARTIN-JONES, Marilyn; JONES, Kathryn (Orgs). Multilingual Literacies: reading and writing different worlds. Jonh Benjamins. 2000.

What's "new" in New Literacy Studies? Critical approaches to literacy in theory and practice. Current Issues in Comparative Education, Teachers College, Columbia University. v, 5(2), 2003. p.77-91.

Futures of the ethonography of literacy? Language and Education. King's College, London, UK. Vol.18. n.4, 2004. p.326-330.

Perspectivas interculturais sobre o letramento. Revista Filologia e Linguística Portuguesa. $N^{\circ}$ 8, 2006, p. 465-488.

; LEFSTEIN, A. Literacy an advanced resource book for student. Canada: Routledge, 2007.

TUSTING, K. The new literacy studies and time: an exploration. In: BARTON, D; HAMILTON, M; IVANIC, R (Orgs) Situated literacies: reading and writing in context. Londres e Nova York: Routledge, 2000.

WEI, Li. Research Perspectives on Bilingualism and Multilingualism. In: WEY, Li; MOYER, Melissa G. The Blackweel Guide to Research Methods in Bilingualism and Multilingualism. Blackwell Publishing, 2008. 